\title{
Co-Existence and Convergence: Confucianism, Taoism and Buddhism in the Book Cai Gen Tan
}

\author{
Fred Y. Ye \\ iSchool, Nanjing University, Nanjing, China \\ Email: yye@nju.edu.cn
}

Received October 23 ${ }^{\text {rd }}$, 2013; revised November 23 $3^{\text {rd }}$, 2013; accepted December $1^{\text {st }}, 2013$

\begin{abstract}
Copyright (c) 2014 Fred Y. Ye. This is an open access article distributed under the Creative Commons Attribution License, which permits unrestricted use, distribution, and reproduction in any medium, provided the original work is properly cited. In accordance of the Creative Commons Attribution License all Copyrights (c) 2014 are reserved for SCIRP and the owner of the intellectual property Fred Y. Ye. All Copyright (C) 2014 are guarded by law and by SCIRP as a guardian.
\end{abstract}

Cai Gen Tan is a key book that fuses Confucianism, Taoism, and Buddhism. Written in essay form that integrates maxims and epigrams, the book Cai Gen Tan suggests ways toward a simple, peaceful, and quiet mind and life, while promoting philosophical values for contemporary society and communicating Eastern thoughts to Western world.

Keywords: Cai Gen Tan; Confucianism; Taoism; Buddhism

\section{Introduction}

It is well known that there existed merging and interpenetration of Confucianism, Taoism and Buddhism in Chinese philosophy, after the Tang dynasty (618-907), particularly during the Song dynasty (960-1279) and Ming dynasty (1368-1644). A book that became important evidence was Cai Gen Tan, or Tending the Roots of Wisdom, translated by Paul White (2001), written by Yingming Hong during the Wanli reign (1573-1620) of the Ming Dynasty. Another English translation is My Crude Philosophy of Life, translated by Jiansong Jiang (2001) ${ }^{1}$.

Cai Gen Tan is a key book that fuses Confucianism, Taoism and Buddhism. Written in essay form, it is a book that integrates maxims and epigrams about how to conduct one's life properly, dealing with, among other things, how to cultivate one's moral character and temperament, how to put one's mind at peace, how to conduct oneself in society, and how to get along with people. Employing a wealth of quotations and elegant phrasing, its observations explain profound truths in simple terms and provide great ideas for contemplation. This book takes Chinese philosophy from metaphysics into everyday life.

In the 400 or so years following its first appearance, the book was not widely disseminated either at home or abroad, and was not well known. Throughout the 20th century, it failed to arouse much attention in philosophical, literary, or artistic circles in China. But in Japan a different situation arose in the 1980s, when a "Cai Gen Tan craze" swept the business world. A number of Japanese corporations, impressed with the philosophical

\footnotetext{
${ }^{1}$ There are two main English versions of the Book Cai Gen Tan. One is White, P. (tr.) Tending the Roots of Wisdom, Beijing: New World Press, 2001 and 2003 (in Library of Chinese Classics); and another is Jiang, J. S. (tr.) Cai Gen Tan: My Crude Philosophy of Life, Changsha: Hunan People's Press, 2001. Mostly, Jiang's translation version seems better that White's. Refer Guo, Z.Z. A Discussion on the Book Cai Gen Tan and Its Two English Versions, Foreign Languages and Their Teaching, 2005(12): 48-51 (Chinese).
}

approach of the work, adopted it as a component of their management concepts. Everyone can adopt the Confucian virtue of "self-cultivation" along with the Taoist and Buddhist doctrine of "returning to simplicity and the unadorned truth". Cai Gen Tan is filled with precepts stressing self-cultivation.

Now that Cai Gen Tan is well known in Eastern world and the two translations have been published, we have the opportunity to discuss it with English speakers.

\section{Characteristics of Confucianism, Taoism and Buddhism}

\section{Confucianism}

Confucianism is a Chinese ethical and philosophical system developed from the teachings of the Chinese philosopher Confucius (Master Kung, 551-479BC) ${ }^{2}$. It focuses on human morality and right action. Confucianism is a complex system of moral, social, political, philosophical, and quasi-religious thought that has had tremendous influence on the culture and history of East Asia. It might even be considered the state religion of some East Asian countries, because of governmental promotion of Confucian values. The core beliefs of Confucianism include five virtues and three immortals. The five virtues are Jen (Ren, benevolence), Yi (righteousness), Li (propriety), Chi (Zhi, wisdom) and Hsin (Xin, honesty and trustworthiness), in which Jen and $\mathrm{Li}$ are of core importance. Jen means benevolence, or humaneness towards others; $\mathrm{Li}$ includes ritual, propriety, and etiquette. Internal Jen and external Li construct the ideal humanity of Confucianism. Meanwhile, Chung (Zhong, loyalty to the state) and Hsiao (Xiao, love within the family, love of parents for their children and of children for their parents) are also important values for state and family respectively. The Three Im-

${ }^{2}$ Ref. Yao, Xinzhong. An Introduction to Confucianism, Cambridge: Cambridge University Press, 2000; and

http://en.wikipedia.org/wiki/Confucianism 
mortals mean to maintain virtues (Li De), to make contributions (Li Gong), and to write great words ( $\mathrm{Li}$ Yan). Together these constitute a gentleman's life.

The Confucian spirit is recorded in Four Books (The Great Learning, The Doctrine of the Mean, The Confucian Analects, The Works of Mencius) and Five Classics (The Book of Changes, or I Ching; The Book of History; The Book of Poetry; The Book of Propriety; The Book of Spring-Autumn). The Confucian Analects (Lunyu) recorded the sayings of Confucius and the Works of Mencius Mengtze (Mengzi).

\section{Taoism}

Taoism is another Chinese philosophical and religious tradition $^{3}$ that has influenced East Asia for over two thousand years and has spread internationally. The Chinese character Tao (Dao) means "way" or "path", although in Chinese philosophy it has taken on more abstract meanings. The Tao is also associated with another complex concept of Te (De), which means "virtue, integrity, power", that is, the active expression of Tao. Te is the active living, or cultivation, of the Tao. So the core beliefs of Taoism follow the Tao Te Ching, in which one is suggested to embody naturalness, vitality, peace, non-action (Wu Wei), emptiness (refinement), detachment, the strength of softness (or flexibility), and receptivity and spontaneity. Taoist thought and life focus on health, longevity, and immortality. In Taoist philosophy, the core ideas are emptiness and non-action, so that human life is quiet and happy; Taoists like to enjoy life.

Taoists believe that humanity is a microcosm of the universe. The body ties directly into the Chinese five elements, Gold (Jin), Wood (Mu), Water (Shui), Fire (Huo) and Soil (Tu). And five organs correlate with the five elements, as do the five parts of all things. Various rituals, exercises, and substances are said to positively affect one's physical and mental health. These concepts are basic to Taoism in its elite forms. Internal alchemy and various spiritual practices are used by some Taoists to improve health and extend life, theoretically even to the point of physical immortality.

Taoist classics are mainly the Tao Te Ching (Lao Zi) and Chuangtze (Zhuang Zi), which reflect the Taoist spirit.

\section{Buddhism}

Buddhism is a family of beliefs and practices, considered by many to be a religion. There are many different schools, but only two major branches ${ }^{4}$ : Mahayana (including Pure Land, Zen, Nichiren and Vajrayana, found throughout East Asia) and Theravada (which has a widespread following in Southeast Asia).

The basic Buddhist concepts originate from ideas about cause and effect (Karma). Buddhism introduced the Four Noble Truths, the Noble Eightfold Path, the Three Jewels, and other Buddhist theories and practices.

The Four Noble Truths are "suffering", "the arising of suffering", "the end of suffering", and "the way leading to the end of suffering”. The first truth is that life always incorporates suffering or Dukkha as it was called then (Dukkha has a broader meaning than suffering. It can be the feeling you experience

${ }^{3}$ Ref. Hansen, Chad D. A Daoist Theory of Chinese Thought: A Philosophical Interpretation, Oxford: Oxford University Press, 2000; and http://en.wikipedia.org/wiki/Taoism

${ }^{4}$ Ref. Gethin, Rupert. Foundations of Buddhism, Oxford: Oxford University Press, 1998; and http://en.wikipedia.org/wiki/Buddhism when you encounter pain, old age, sickness, loss, or separation from loved ones, but it can also represent a general unsatisfied feeling). The second noble truth is that suffering in its broad sense comes from desire, and specifically, desire for meeting our expectations and for self-fulfillment as we see it. By desiring for ourselves rather than for the whole, we will always have suffering. The third noble truth tells us that if our attachment to desire ends, so too will suffering. This is not intended to negate of the zest for life, but to lead to an understanding of the nature of life and to controlling those desires which come from that lack of understanding. The fourth noble truth shows the way to end suffering. The Buddha said that the way to lessen suffering is to follow the middle way of the Noble Eightfold path. This provides the guidelines for day to day living. There is some analogy here with the Ten Commandments in Christianity, but the eightfold path is meant as a guide rather than as a strict rule.

The Noble Eightfold Path is the way to the cessation of suffering, which consists of Right Understanding, Right Intent, Right Speech, Right Action, Right Livelihood, Right Effort, Right Mindfulness, and Right Concentration. The eightfold path, although referred to as steps on a path, is not meant as a sequential learning process, but as eight aspects of life, all of which are to be integrated in everyday life. Thus the environment is created to move closer to the Buddhist path. The eightfold path is at the heart of the middle way, which turns away from extremes, and encourages us to seek a simple approach.

The three Jewels are the Buddha, the Dharma (which is the teaching of the Buddha), and the Sangha (which is the community who follow the teaching). When a person accepts the Buddhist philosophy and wants to make it part of their life, the traditional way is to say "I take refuge in the Buddha, I take refuge in the Dharma, and I take refuge in the Sangha”.

Buddha thought that the essence of life was suffering, so he was compassionate to all creatures. As Buddhists follow this philosophy, they practice a disciplined life and a clear commitment to liberation. The Buddha laid out a clear path to this goal and also observations on how to live life wisely. The core of this teaching is contained in the Noble Eightfold Path, which includes the three essential areas of Buddhist practice: ethical conduct, mental discipline (concentration or meditation), and wisdom. The goal is to cultivate both wisdom and compassion, which together will enable one ultimately to attain enlightenment.

Chinese Buddhism belongs to the Mahayana tradition, which the Cai Gen Tan absorbed in its essential spirit.

\section{The Co-Existence of Confucianism, Taoism and Buddhism in Cai Gen Tan}

During the Song and Ming dynasties, Confucianism, Taoism and Buddhism mingled and penetrated Chinese philosophy and culture. The core thoughts were integrated into the Cai Gan Tan, in which the thoughts of Confucianism, Taoism, and Buddhism co-exit.

In Cai Gan Tan, we can feel Confucian Jen and Li, for example:

Do not go against one's own conscience; do not frustrate others' feelings; do not exhaust material resources. The above three things can develop a kind nature for the universe, create an eternal life for the populace, and bring in- 
finite happiness to posterity (Jiang's translation, No. 320).

Here, "do not go against one's own conscience" corresponds to Jen, and "do not frustrate others' feelings" means Li. This is similar to Confucian teachings.

Meanwhile, in the Confucian Analects, the Master said, "Riches and honors are what men desire. If it cannot be obtained in the proper way, they should not be held. Poverty and meanness are what men dislike. If it cannot be obtained in the proper way, they should not be avoided. If a superior man abandons virtue, how can he fulfill the requirements of that name? The superior man does not, even for the space of a single meal, act contrary to virtue. In moments of haste, he cleaves to it. In seasons of danger, he cleaves to it." (The Confucian Analects, 4.5, translated by James Legge $)^{5}$. Similar sentences were invented by the author of book Cai Gan Tan, for example:

Rich and honor is a cold-hearted thing: the more you value it, the greater harm it does to you; poverty and lowliness is a devoted friend: the kinder you are to it, the greater benefit you receive from it. Thus both King Hui of Chu and the Jin dynasty millionaire Shi Chong met their deaths because of their illustriousness at the time, the one for coveting the Qin territory of Shangyu, the other for loving the famous Garden of Jingu. By contrast, the Confucian disciples Yan Hui and Zi Lu both won a lasting name, the one happy to live on a bowlful of rice and a ladleful of water, the other contented to be clad in rags (Jiang's translation, No. 124).

This Confucian idea is illustrated by a Confucian story, which Yan Hui, one of Confucian's students, recorded in the Confucian Analects: the Master said, "Admirable indeed was the virtue of Hui! With a single bamboo dish of rice, a single gourd of drink, and living in his mean narrow lane, while others could not have endured the distress, he did not allow his joy to be affected by it. Admirable indeed was the virtue of Hui!" (The Confucian Analects, 6.11, translated by James Legge).

So, we see that the author of book Cai Gan Tan followed Confucian thought.

We can also meet non-action, emptiness and other Taoist ideas in Cai Gan Tan, such as:

When one's state of mind is crystal clear, one will always be in a condition as smooth and unruffled as a mirror or still water, and naturally there will be nothing disagreeable in the world; when one's temperament is mild and peaceful, one will always be in a state as soothing and pleasant as bright sun and gentle breeze, and certainly there will be no one hateful in the nation (Jiang's translation, No. 42).

In the day, when one is idle and all human stir absent, a few melodious warbles of birds and you will feel the sound so crisp and clear; at night, when all is quiet and the sky seems so high, a slowly spreading cloud and you will feel your vision so open and vast (Jiang's translation, No. 138).

These ideas are reflections of non-action and emptiness via a peaceful and quiet mind from Taoism, in which we see a natu-

\footnotetext{
${ }^{5}$ There exist some English versions of the Confucian Analects, of which James Legge's translation and Arthur Waley's translation are popular. Here, Legge's translation is adopted.
}

ral and happy Taoist.

Some Taoist fables can also be found in the book Cai Gan Tan, for example:

Seeing the land so vast and the sky so high, one feels even the roc's flight of 10,000 li covers only a limited distance; seeing the clouds so dense and the pines so old, one realizes how leisurely the crane's dream must be (Jiang's translation, No. 161).

In the paragraph above, the author cited the fable from Chuangtze, "In the north sea, there was a kind of fish, Kun, whose size covered thousands of li. The fish metamorphosed into a kind of bird, Peng (roc), whose back covered thousands of li. When it rose in flight, its wings were like clouds that hung from the sky." (Chuangtze, Chapter 1). Tan.

So, Taoism is also an important source for the book Cai Gan

And For Buddhism, its thoughts exist almost everywhere in Cai Gan Tan, such as

When the body of limited duration is seen through, material concerns of all circumstances will cease; when a state of carefree enlightenment is reached, the mind will shine bright and clear like the moon (Jiang's translation, No. 152).

A mere kind idea can bring harmony to the world; a mere pure mind can leave a good name to posterity (Jiang's translation, No. 316).

Here we can see Buddhist compassion and wisdom, which enlighten the human mind and guide human life.

\section{The Convergence of Confucianism, Taoism, and Buddhism in Cai Gen Tan}

Besides the above mentioned contents, other sentences in the book Cai Gne Tan mingle Confucianism, Taoism and Buddhism. We can meanwhile see active Confucians, compassionate Buddhists, and natural Taoists in the Book Cai Gen Tan, where more aphorisms display the interpenetration of Confucianism, Taoism and Buddhism, such as

With the physical self, one should be disillusioned, for then everything will be void, and one's mind will always be empty and unoccupied; when one's mind is empty and unoccupied, reason and truth will come to reside. With the spiritual self, one should be earnest, for then every truth will be present, and one's mind will always be occupied and full; when one's mind is occupied and full, material desires will not find entrance (Jiang's translation, No. 18).

Here, we can see Confucian reason, Taoist emptiness, and Buddhist mind. The concepts of Confucianism, Taoism and Buddhism have been amalgamated.

Sometimes, Confucian and Taoist lifestyles have been fused, for example:

Reading verse and prose classics in a thatched cottage, one meets and discourses with sages and men of virtue every day: who can say poverty is a sorrow? Drinking in the open with the heaven as canopy and the earth as mattress, one mingles and interacts with nature all time: who can say getting drunk is not meditation? (Jiang's translation, No. 145). 
The person reading looks Confucian and the one drinking looks Taoist, while the following sentence shows a sleeping Buddhist.

When, on the spur of the moment, one gets drunk and sleeps before falling petals, heaven and earth will be like quilt and pillow; when, free from calculation, one sits oblivious on a rock, all history will seem as short lived and transient as mayflies (Jiang's translation, No. 146).

So, we can understand that the author of Cai Gen Tan promotes a simple, peaceful and quiet life:

Be simple and artless rather than smart and wise, so as to leave some righteousness in the universe; reject extravagance rather then keep worldly desires, so as to leave a good name in the world (Jiang's translation, No. 213).

\section{And}

Be never disturbed by either favor or disfavor, but rather leisurely watch flowers bloom and fade in the courtyard; be always indifferent to both promotion and demotion, and idly imagine yourself gathering or dispersing with the clouds in the sky (Jiang's translation, No. 364).

In the Tao Te Ching, Taoist propriety and ethics emphasize the Three Treasures, as it is said, "I have three treasures that I hold and guard. The first is kindness. The second is simplicity. The third is humbleness. With kindness, one can be brave. With simplicity, one can be generous. With humbleness, one can become perfect as chief of all." (Chapter 67) ${ }^{6}$. This is similar to the Three Immortals of Confucianism and the Three Jewels of Buddhism, all of which can be summed up to be humility, moderation, and compassion. These construct the unification of Confucian, Taoist and Buddhist philosophies, as well as the unification of Confucian, Taoist and Buddhist lifestyles.

Now, we know that the Cai Gen Tan was the key book that successfully merged Confucian, Taoist and Buddhist philosophies. Although philosophers ignored its thoughts, many people applied them into practice. So, its spirit penetrated the popular mind and social culture, particularly in Asian countries.

\section{The Contemporary Philosophical Values of Cai Gen Tan}

In contemporary society, business dominates every corner. This activity, produces economic development and technical progress, but the human mind has lost its peace and quietness. In this complex age, the human mind needs a spiritual garden. The book Cai Gen Tan provided this.

In the book Cai Gen Tan, active Confucians, compassionate
Buddhists and natural Taoists show us Confucian, Taoist and Buddhist spirits of humility, moderation, and compassion, as well as their simple, peaceful, and quiet lifestyles, which are valuable in contemporary society.

We know there are different value systems among the various philosophies. The book Cai Gen Tan provides us a unique reference system of value, which differs from the predominant Western one, where values are God-given. In Cai Gen Tan, the values are set out as objectivity and naturalness, which lead to a simple, peaceful, and quiet mind and life.

In Chinese philosophy, after Song dynasty, Confucianism, Taoism and Buddhism were merged together, so it was normal and reasonable that co-existence and convergence of Confucianism, Taoism and Buddhism happened in the book Cai Gen Tan which produced in Ming dynasty. Hundreds years later, might we accept it as a philosophical value choice in contemporary society?

If we would learn wisdom from the book Cai Gen Tan, we could establish a foundation for the human mind to have a happy life and maintain a peaceful world. This is the most important contemporary value of the book Cai Gen Tan, particularly in intercultural communication and international understanding.

\section{Conclusion}

Cai Gen Tan is a key book that fuses Confucianism, Taoism and Buddhism. Cai Gen Tan takes Chinese philosophy from metaphysics into everyday life. It integrates maxims and epigrams dealing with, among other things, how to cultivate one's moral character and temperament, how to put one's mind at peace, how to conduct oneself in society, and how to get along with people. It suggests simple, peaceful, and quiet mind and life so that it provides a synthetic referable and valuable philosophy for contemporary society and culture, in both Asia and America, East and West.

\section{Acknowledgements}

The author is grateful to Ms. Regina Entorf at Wittenberg University in USA for her English wording and comments.

\section{REFERENCES}

Jiang, J. S. (2001). Cai Gen Tan: My crude philosophy of life. Changsha: Hunan People's Press (Chinese-English Bilingual Edition).

White, P. (2001). Tending the roots of wisdom. Beijing: New World Press (Chinese-English Bilingual Edition). 